\title{
The impact of stress on financial decision-making varies as a function of depression and anxiety symptoms
}

Oliver J Robinson, Rebecca Bond, Jonathan P Roiser

Stress can precipitate the onset of mood and anxiety disorders. This may occur, at least in part, via a modulatory effect of stress on decision-making. Some individuals are, however, more resilient to the effects of stress than others. The mechanisms underlying such vulnerability differences are nevertheless unknown. In this study we attempted to begin quantifying individual differences in vulnerability by exploring the effect of experimentally induced stress on decision-making. Threat of unpredictable shock was used to induce stress in healthy volunteers ( $\mathrm{N}=47)$ using a within-subjects, within-session design, and its impact on a financial decision-making task (the lowa Gambling Task) was assessed alongside anxious and depressive symptomatology. As expected, participants learned to select advantageous decks and avoid disadvantageous decks. Importantly, we found that stress provoked a pattern of harm-avoidant behaviour (decreased selection of disadvantageous decks) in individuals with low levels of trait anxiety. By contrast, individuals with high trait anxiety demonstrated the opposite pattern: stress-induced riskseeking (increased selection of disadvantageous decks). These contrasting influences of stress depending on mood and anxiety symptoms might provide insight into vulnerability to common mental illness. In particular, we speculate that those who adopt a more harmavoidant strategy may be better able to regulate their exposure to further environmental stress, reducing their susceptibility to mood and anxiety disorders. 
2 The impact of stress on financial decision-making varies as a function of depression and anxiety symptoms

3

4 Oliver J Robinson*, Rebecca L Bond, Jonathan P Roiser

5 Institute of Cognitive Neuroscience, University College London, UK

6

$7 \quad *$ Corresponding Author: oliver.j.robinson@gmail.com

8

9 UCL Institute of Cognitive Neuroscience - 17 Queen Square - London - WC1N 3AR

10

$11 \quad+44(0) 2076791177$

12

13

14

15

16 
18 It is well established that stress can precipitate mood and anxiety disorders (de Kloet et al., 2005). However, it

19 is also recognised that there exist great differences amongst individuals; some individuals are resilient to

20 stress, whilst others are particularly vulnerable (Kendler et al., 2004). However, the neural and behavioural

21 mechanisms underlying such individual differences in vulnerability remain poorly understood. One potential

22 mechanism by which stress might contribute to mood disorder vulnerability is via its modulatory impacts on

23 behaviour (Dias-Ferreira et al., 2009, Robinson et al., 2013). In this study we sought to explore how the impact

24 of stress on behaviour might vary as a function of individual differences in mood and anxiety symptoms.

25 We explored the impact of stress on performance of a well-validated financial decision-making paradigm: the lowa gambling task (Bechara et al., 1994). In this task, healthy individuals learn to play from 'advantageous' decks of cards - which result in net gains across repeated selections - and to avoid 'disadvantageous' decks, which result in net losses (Maia and McClelland, 2004). To induce stress during this task we used the wellvalidated (Robinson et al., 2013, Grillon, 2008, Davis, 2006, Davis et al., 2010) within-subject, within-session, threat of unpredictable shock paradigm, which has been shown to increase reliably the psychological

31 (Robinson et al., 2013), physiological (e.g. startle responding (Schmitz and Grillon, 2012, Grillon, 2008, Grillon

32 et al., 1991)) and neural (Mechias et al., 2010, Vytal et al., 2014, Davis, 2006, Robinson et al., 2012a)

33 concomitants of anxiety, in both humans and experimental animals (Davis, 2006, Davis et al., 2010). To explore

34 individual differences in stress reactivity we recruited a sample of individuals self-identifying as healthy but

35 reporting a range of trait anxiety and depression scores.

36 A small amount of prior work has explored the influence of stress on this task. Social stress - induced by threat

37 of unprepared public speaking on the Trier social stress test - has been reported to reverse the adaptive bias

38 towards advantageous decks, triggering increased selection of disadvantageous decks (Preston et al., 2007, van

39 den Bos et al., 2009) (albeit only in some individuals in a complex interaction with individual differences). 
40 Other work has shown that individuals at risk of anxiety disorders (Miu et al., 2008), depressed individuals

41 (Must et al., 2013) and individuals with chronic pain (Walteros et al., 2011) also show an attenuation of this

42 adaptive bias due to increased selection of disadvantageous decks. However, others reported reduced

43 selection of disadvantageous decks in individuals with high trait anxiety (Mueller et al., 2010, Werner et al.,

44 2009). What might underlie these discrepancies is unclear. Given the critical interplay between trait

45 vulnerability and environmental stress in stress-diathesis models of mood and anxiety disorders (Kendler et al.,

46 2004), it is important to understand the degree to which vulnerability and response to stress interact to

47 influence decision making behaviour.

48 Based on prior results, we predicted that our healthy sample as a whole would demonstrate a bias towards

49 avoiding disadvantageous decks at baseline (Bechara et al., 1994, Maia and McClelland, 2004), and that this

50 bias would reverse under threat of shock (Preston et al., 2007, van den Bos et al., 2009). In our key exploratory

51 analysis we also examined the interaction between stress and mood/anxiety symptoms on task performance.

52 Based on epidemiological evidence for increased pathological mood/anxiety symptoms following stress in

53 vulnerable individuals (Kendler et al., 2004) and prior reports of greater disadvantageous deck selection in

54 individuals with anxious and depressive symptomatology (Miu et al., 2008, Must et al., 2013), we predicted

55 that individuals with high trait vulnerability would exhibit maladaptive responses to stress, resulting in a

56 reduction in the bias towards selecting advantageous decks.

\section{Methods}

\section{Participants}

60 Forty-seven participants completed the experiment (31 female: 16 male; mean age $=22.8$, s.d. $=4.23$ ). Ethical

61 approval was obtained from the UCL Research Ethics Committee (1764/001). Participants were recruited via 
responses to an advertisement through the UCL Institute of Cognitive Neuroscience Subject Database and provided written informed consent. All subjects completed a screening form in which they reported that they were healthy with no history of psychiatric, neurological or cardiovascular diagnosis.

\section{Procedure}

Stress was induced by unpredictable electrical shocks delivered using a Digitimer DS7A Constant Current Stimulator (Digitimer Ltd., Welwyn Garden City, UK), with an electrode secured to the wrist. A shock work-up procedure standardised the level of shock for each individual. During the threat block the screen was red and displayed a message "YOU ARE NOW AT RISK OF SHOCK" whereas in the safe block the screen was blue with the message "YOU ARE NOW SAFE FROM SHOCK". Participants were informed:

- $\quad$ You will alternate between safe conditions, where you will receive NO shocks, and threat conditions, where you might receive a shock at ANY time. THREAT conditions are indicated by a RED background, SAFE conditions are indicated by a BLUE background

- $\quad$ The shock is unpredictable and unrelated to your task performance but may come at any time during the threat condition.

At the end of each block, participants indicated how anxious they had felt during each of the threat and safe conditions on a scale from 1 ("not at all") to 10 ("very much so"). This manipulation check has been used in numerous studies (see (Robinson et al., 2013) for a review). Participants also provided self-report measures of depression (Beck Depression Inventory; BDI) (Beck and Steer, 1987) and trait anxiety (State Trait Anxiety Inventory: STAI) (Spielberger et al., 1970) at the end of the session.

\section{lowa Gambling Task}

We adopted a forced-choice version of the lowa Gambling task (Figure 1) which enabled us to explore choice behaviour for all conditions (Cauffman et al., 2010)(Table 1). On each trial, one of four decks of cards was 
highlighted in a pseudo random order (resulting in a minimum of 20 opportunities to reject each deck) by a yellow border, and the participant had to choose whether to play or pass that deck. If they chose to play, the participant was shown a monetary outcome (win, loss or no change), and a running monetary total displayed on-screen changed accordingly. If they passed, the next deck was selected (with no change in the monetary total). If no response was made within 4 seconds the card was passed automatically. The probabilities and magnitudes of win and loss outcomes varied between decks such that two of the decks provided a net monetary gain on average if played repeatedly (advantageous decks; Table 1), while the other two decks provided a net loss (disadvantageous decks; Table 1). Participants played the game twice, once under threat of shock and once while safe (order counterbalanced) starting with new decks and a hypothetical $\$ 2,000$ total in each of these two blocks. Each block consisted of 120 trials. Two shocks were delivered during the threat block (after the $13^{\text {th }}$ and $58^{\text {th }}$ trials). Participants were shown illustrated task instructions and completed 12 practice trials prior to their first block of the task.

\section{Analysis}

Choice behaviour and reaction times were analysed using repeated-measures general-linear models (with between and within-subjects factors) in SPSS version 22 (IBM Corp, Armonk, NY). Data from the two advantageous and the two disadvantageous decks were pooled prior to analysis resulting in two choice variables. Choice behaviour (proportion of cards accepted) was then analysed in 3-way deck (advantageous, disadvantageous) $\mathrm{x}$ stress (threat, safe) $\mathrm{x}$ symptom (depression/trait anxiety as a continuous variable, in separate analyses) ANCOVAs. Post-hoc analyses were performed using Pearson's r correlations between symptom measures and a measure of the impact of threat on choice (threat minus safe). Reaction time data were analysed in four-way deck (advantageous, disadvantageous) $x$ stress (threat, safe) $x$ decision (play, pass) $x$ symptom (depression/trait anxiety as a continuous measure) ANCOVAs. Note that only $\mathrm{N}=42$ participants could be included in the reaction-time analysis as 5 never passed one or more of the decks and thus had incomplete 
107 reaction time data. Trait anxiety (mean $=41$, a range $=21-64$, standard deviation $=11$ ) was normally

108 distributed (Shapiro-Wilk test, $p=0.28$ ), but BDI (mean $=6$, range $=0-26$, standard deviation $=6$ ) was skewed

109 towards lower values (Shapiro-Wilk test, $\mathrm{p}<0.001$ ) so a square root transformation was applied prior to

110 analysis. For all analyses $\mathrm{P}=0.05$ was considered significant. Based on the meta-analytic effect size of -0.58 for

111 the lowa gambling task (Mukherjee and Kable, 2014), $\mathrm{t}$-test analysis in our sample $(\mathrm{N}=41$ ) has an $~ 84 \%$ power

112 to detect an effect size of alpha 0.01 (two-tailed). All data can be downloaded from figshare:

113 http://dx.doi.org/10.6084/m9.figshare.1257693.

\section{Results}

\section{Individual differences and manipulation check}

116 There was a strong correlation between depression and trait anxiety measures $(r(47)=0.74, p<0.0001)$.

117 Subjects rated themselves as significantly more anxious $(F(1,46)=85.3, p<0.0001, \eta 2=0.65)$ during the threat

118 condition $($ mean $=4.7 / 10$, standard deviation $=2.3$ ) than the safe condition $($ mean $=1.8 / 10$, standard deviation

$119=1.2)$. This was not influenced by trait anxiety $(F(1,45)=0.004, p=0.95, \eta 2=0.00009)$ or depression

$120(F(1,45)=0.42, p=0.52, \eta 2=0.009)$ and there was no impact of order $(F(1,45)=0.3, p=0.6 \eta 2=0.007$. There was no

121 impact of manipulation order on trait anxiety $(F(1,45)=0.2, p=0.7)$ or $B D I(F(1,45)=0.3, p=0.6)$.

\section{Choice behaviour}

123 We found a significant main effect of deck type (greater selection of advantageous decks: $F(1,46)=36.2$,

$124 p<0.001, \eta 2=0.44)$ but no stress by deck interaction $(F(1,46)=0.43, p=0.51, \eta 2=0.009 ;$ Table 2$)$. However,

125 including trait anxiety in the model revealed a significant stress $x$ deck $x$ trait anxiety interaction $(F(1,45)=6.4$,

$126 \mathrm{p}=0.015, \mathrm{\eta} 2=0.13$ ) which was driven by a significant correlation between trait anxiety and stress-triggered

127 propensity to play disadvantageous decks $(r(47)=0.336, p=0.021)$ but not advantageous decks $(r(47)=-$

$1280.065, p=0.66$; significant difference between correlations: Steiger's $Z=1.96, p=0.05$; correlation with a 
129 compound advantageous vs disadvantageous deck variable: $r=-0.35, p=0.015)$. In other words, we observed

130 (along a continuum) stress-potentiated harm-avoidance in individuals with no/low anxiety symptoms, but the

131 opposite pattern - stress-potentiated risk-seeking - in individuals with moderate anxiety symptomatology

132 (Figure 2). This was seen in the absence of a trait anxiety $x$ deck interaction $(F(1,45)=1.1, p=0.31)$.

133 Substituting trait anxiety for BDI in the model revealed a similar pattern of results. Critically, the significant

134 stress $x$ deck $x$ depression interaction $(F(1,45)=8.9, p=0.005, \eta 2=0.17)$ was also driven by a significant

135 correlation between depression scores and threat-potentiated task performance for disadvantageous decks

$136(r(47)=0.415, p=0.004)$ but not advantageous decks $(r(47)=-0.012, p=0.94$; significant difference between

137 correlations: Steiger's Z=-2.1, p=0.03; correlation with a compound advantageous vs disadvantageous deck

138 variable: $r=-0.41, p=0.005$; Figure 2). Again, no depression $x$ deck interaction was seen $(F(1,45)=1.3, p=0.27)$.

139 Including both trait anxiety and depression scores in the same model resulted in the symptom $\mathrm{x}$ diagnosis $\mathrm{x}$

140 deck interactions becoming non-significant (depression, $p<0.12$; anxiety, $p<0.57$ ) indicating that the two scales

141 account for the same variance in this sample.

142 There was a three-way manipulation order $x$ stress $x$ deck interaction $(F(1,45)=12, p=0.001$, partial $\eta 2=0.2)$ as

143 subjects were more likely to avoid the disadvantageous decks on their second block irrespective of condition.

144 However, this learning effect was orthogonal to our effects of interest: including order had little impact on the

145 results (trait; $p=0.012, \eta 2=0.14 ; B D I p=0.004, \eta 2=0.17$ ), and neither did including order in partial correlations

146 between symptoms and threat-potentiated task performance for disadvantageous decks (trait; $r=0.344$,

$147 \mathrm{p}=0.019 ; \mathrm{BDI} r=0.419, \mathrm{p}=0.004)$.

\section{Reaction times}

149 Subjects were faster to play than to pass cards $\left(F(1,41)=26, p<0.001, \eta^{2}=0.39\right)$ but there was no main effect of 150 stress $\left(F(1,41)=0.008, p=0.93, \eta^{2}<0.001\right) \operatorname{deck}\left(F(1,41)=0.33, p=0.56, \eta^{2}=0.008\right)$ or stress $x$ deck interaction 
$151\left(F(1,41)=0.004, p=0.95, \eta^{2}<0.001 ;\right.$ Table 2$)$. Including symptoms in the model revealed no stress $x$ deck $x$ trait

152 anxiety interaction $\left(F(1,40)=0.256 p=0.62, \eta^{2}=0.006\right)$ or stress $x$ deck $x$ depression interaction $(F(1,40)=0.02$, $\left.153 p=0.89, \eta^{2}<0.001\right)$.

\section{Post-hoc exploration of deck acceptance rates}

155 Some participants $(\mathrm{N}=5)$ failed to reject one of the four decks whenever it was presented. On the suggestion of

156 one of the reviewers, to explore this further, we divided the sample into individuals who accepted any given

157 deck more than $90 \%$ of the time $(\mathrm{N}=23)$, and those who did not $(\mathrm{N}=24)$. This 'high acceptance' rate (which was

158 almost entirely driven by advantageous decks) showed an interaction with symptoms. Those who accepted any

159 deck greater than $90 \%$ of the time showed significantly lower trait anxiety $(F(1,45)=6.7, p=0.012)$ and

160 depression scores $(F(1,45)=9.5, p=0.003)$.

\section{Discussion}

162 The current study demonstrates an interaction between sub-clinical mood/anxiety symptoms and stress-

163 responses on decision-making behaviour. Specifically, we found opposite stress-responses in those with low -

164 versus those with moderate- anxiety and depression symptoms. On the one hand, individuals with low

165 depressive symptoms displayed a pattern of stress-potentiated harm-avoidance, whilst those with moderate

166 symptoms show an opposing pattern of stress-potentiated risk-seeking.

167 We replicated the frequently reported pattern of harm avoidance on the IGT across our sample as a whole

168 (Maia and McClelland, 2004). Specifically, across all individuals, we saw a pattern of increased selection of

169 advantageous over disadvantageous decks. We did not see, however, the predicted increase in selection of

170 disadvantageous decks under stress across the whole sample. A close reading of prior findings indicates that

171 this is likely a replication (Preston et al., 2007, van den Bos et al., 2009). The present study nevertheless

172 extends our understanding of the role of stress to show that in individuals with low depression or anxiety 
173 symptomatology a baseline harm avoidant strategy (i.e. increased selection of advantageous vs.

174 disadvantageous decks) is increased by stress. That is to say, low symptomatic individuals are even more likely

175 to avoid risky decks under the stress condition relative to their individual baseline. This relative harm avoidant

176 behaviour under stress may therefore be adaptive. Specifically, in conditions of threat, it may be wise to seek

177 to minimise further loss. On the IGT this leads to fewer negative outcomes which, in a naturalistic setting,

178 might mitigate the negative impacts of stress. One possibility, therefore, is that this pattern of stress-induced

179 harm-avoidance and reduced anxious/depressive symptomatology is causally linked. Those who respond in a

180 relatively more harm-avoidant manner to stress might be better at regulating their environmental exposure to

181 sources of stress, and ultimately reduce their vulnerability to mood and anxiety disorders.

182 By contrast, in individuals with moderate symptomatology, the opposite pattern was evident. Stress provoked

183 a pattern of relatively increased risk-seeking as indexed by greater selection of disadvantageous decks under

184 stress. This pattern has been observed in individuals with high mood and anxiety disorder symptomatology

185 (Must et al., 2013, Walteros et al., 2011, Miu et al., 2008), and in response to social stress in some individuals

186 (Walteros et al., 2011, Werner et al., 2009, Preston et al., 2007, van den Bos et al., 2009). Here we extend and

187 integrate these findings to show that this effect is specific to stress-response in symptomatic individuals. On

188 the one hand, this response can be seen as maladaptive. Subjects appear to be seeking further risk, which on

189 average will lead to increased losses on this task, potentially increasing stress exposure in a vicious cycle. On

190 the other hand this might simply reflect an alternative, albeit more risky, strategy. The disadvantageous decks

191 do actually demonstrate larger occasional gains (as well as losses; Table 1). So if a player is lucky, they could

192 potentially more rapidly improve their overall gains, especially if they only occasionally sample from the risky

193 decks. However, in the long run, this strategy will not pay off on the present task and will lead to increased

194 overall losses. This alternative strategy may therefore drive elevated susceptibility to pathological symptoms;

195 the more likely an individual is to adopt relatively more risky strategies, the more vulnerable they are to

196 negative outcomes, associated negative mood states, and hence mood and anxiety disorders. Indeed, there is 
some naturalistic evidence for such a mechanism. Some individuals with high levels of social anxiety

198

199 demonstrate high levels of risk-taking behaviour on questionnaire measures (Kashdan et al., 2006, Kashdan et al., 2008, Kashdan and McKnight, 2010). This may, in turn, explain some of the discrepancies across prior studies. Trait anxiety, for instance, has been shown to be associated with harm-avoidant behaviour on the lowa gambling task in some studies (Mueller et al., 2010) and an opposite pattern of risk-seeking in other studies (Miu et al., 2008). Taking into consideration a given subject's current stress levels may go some way towards explaining this apparent variability.

It is beyond the scope of the present paper to explore the neurochemical basis of this effect, but prior work has shown that the anxiogenic effect of threat of shock is thought to be modulated in part by serotonin and CRH in the amygdala and bed nucleus of the stria terminalis (Davis et al., 2010, Robinson et al., 2012b). It should also be noted that in the present study we were interested in the effect of our manipulation on cognitive measures and as such we did not obtain psychophysiological measures from our participants. Nevertheless, extensive prior work has shown that the threat of shock manipulation reliably and reversibly increases startle responding across humans and animal models (for reviews see (Grillon, 2008, Grillon et al., 1991, Davis et al., 2010, Robinson et al., 2013)). Finally, our paradigm is designed as a translational anxiety/stress induction, but it might be interesting to explore specificity via comparison with other manipulations designed to elicit, for instance, anger or happiness, or with other anxiety manipulations such as oxygen deprivation.

This study raises a number of questions. First, is this effect on disadvantageous decks simply an epiphenomenon of increased current mood disorder symptomatology, rather than underlying vulnerability? From our data we cannot determine the causal relationship between symptoms and stress-induced behavioural change. This question might be addressed through the use of longitudinal designs that follow-up with subjects and determine the relationship between stress-induced behavioural change and subsequent disorder onset. Secondly, why do we see the same effect in trait anxiety and depression scores? Given that 
220 they largely account for the same variance (i.e. including both in the same model leads to both interactions

221 becoming non-significant) this may be because both measures tap into the same broad 'negative affect'

222 construct. The significant positive correlation between the measures in this sample provides further support

223 for this as, indeed, does the observation that Depression and anxiety disorders are highly co-morbid (Kessler et

224 al., 2005). Future work should seek to resolve whether depression and anxiety symptoms actually represent

225 separate constructs at a mechanistic level. Finally, our post-hoc analysis of 'high deck acceptors' (i.e. those who

226 selected any deck more than $90 \%$ of the time) indicates that individuals with lower symptoms might have a

227 greater propensity to explore possibly advantageous choices in the face of uncertainty (i.e. accept over $90 \%$ of

228 uncertain gambles on advantageous decks). This is, of course, speculative, but future work may wish to explore

229 whether this has any functional significance; does it promote resilience to symptoms in some way? 
BECHARA, A., DAMASIO, A. R., DAMASIO, H. \& ANDERSON, S. W. 1994. Insensitivity to future consequences following damage to human prefrontal cortex. Cognition, 50, 7-15.

BECK, A. T. \& STEER, R. A. 1987. BDI, Beck depression inventory: manual, Psychological Corporation New York. CAUFFMAN, E., SHULMAN, E. P., STEINBERG, L., CLAUS, E., BANICH, M. T., GRAHAM, S. \& WOOLARD, J. 2010. Age differences in affective decision making as indexed by performance on the lowa Gambling Task. Developmental Psychology, 46, 193-207.

DAVIS, M. 2006. Neural systems involved in fear and anxiety measured with fear-potentiated startle. Am Psychologist, 61, 741 - 756.

DAVIS, M., WALKER, D. L., MILES, L. \& GRILLON, C. 2010. Phasic vs Sustained Fear in Rats and Humans: Role of the Extended Amygdala in Fear vs Anxiety. Neuropsychopharmacology, 35, 105-135.

DE KLOET, E. R., JOELS, M. \& HOLSBOER, F. 2005. Stress and the brain: from adaptation to disease. Nature Reviews Neuroscience, 6, 463-475.

DIAS-FERREIRA, E., SOUSA, J. C., MELO, I., MORGADO, P., MESQUITA, A. R., CERQUEIRA, J. J., COSTA, R. M. \& SOUSA, N. 2009. Chronic Stress Causes Frontostriatal Reorganization and Affects Decision-Making. Science, 325, 621-625.

GRILLON, C. 2008. Models and mechanisms of anxiety: evidence from startle studies. Psychopharmacology, 199, 421-437.

GRILLON, C., AMELI, R., WOODS, S. W., MERIKANGAS, K. \& DAVIS, M. 1991. Fear-Potentiated Startle in Humans: Effects of Anticipatory Anxiety on the Acoustic Blink Reflex. Psychophysiology, 28, 588-595.

KASHDAN, T., COLLINS, R. L. \& ELHAI, J. 2006. Social Anxiety and Positive Outcome Expectancies on Risk-Taking Behaviors. Cognitive Therapy and Research, 30, 749-761.

KASHDAN, T. B., ELHAI, J. D. \& BREEN, W. E. 2008. Social anxiety and disinhibition: An analysis of curiosity and social rank appraisals, approach-avoidance conflicts, and disruptive risk-taking behavior. Journal of Anxiety Disorders, 22, 925-939.

KASHDAN, T. B. \& MCKNIGHT, P. E. 2010. The Darker Side of Social Anxiety: When Aggressive Impulsivity Prevails Over Shy Inhibition. Current Directions in Psychological Science, 19, 47-50.

KENDLER, K. S., KUHN, J. \& PRESCOTT, C. A. 2004. The Interrelationship of Neuroticism, Sex, and Stressful Life Events in the Prediction of Episodes of Major Depression

10.1176/appi.ajp.161.4.631. American Journal of Psychiatry, 161, 631-636.

KESSLER, R., DEMLER, R., OLFSON, F., PINCUS, H., WALTERS, E., WANG, P., WELLS, K. \& ZASLAVSKY, A. 2005. Prevalence and treatment of mental disorders, 1990 to 2003. N Engl J Med, 352, 2515 - 2523.

MAIA, T. V. \& MCCLELLAND, J. L. 2004. A reexamination of the evidence for the somatic marker hypothesis: What participants really know in the lowa gambling task. Proceedings of the National Academy of Sciences of the United States of America, 101, 16075-16080.

MECHIAS, M.-L., ETKIN, A. \& KALISCH, R. 2010. A meta-analysis of instructed fear studies: Implications for conscious appraisal of threat. Neuroimage, 49, 1760-1768.

MIU, A. C., HEILMAN, R. M. \& HOUSER, D. 2008. Anxiety impairs decision-making: Psychophysiological evidence from an lowa Gambling Task. Biological Psychology, 77, 353-358.

MUELLER, E. M., NGUYEN, J., RAY, W. J. \& BORKOVEC, T. D. 2010. Future-oriented decision-making in Generalized Anxiety Disorder is evident across different versions of the lowa Gambling Task. Journal of Behavior Therapy and Experimental Psychiatry, 41, 165-171.

MUKHERJEE, D. \& KABLE, J. W. 2014. Value-Based Decision Making in Mental Illness: A Meta-Analysis. Clinical Psychological Science. 
MUST, A., HORVATH, S., NEMETH, V. L. \& JANKA, Z. 2013. The lowa Gambling Task in depression - what have we learned about sub-optimal decision-making strategies? Frontiers in Psychology, 4.

PRESTON, S. D., BUCHANAN, T. W., STANSFIELD, R. B. \& BECHARA, A. 2007. Effects of anticipatory stress on decision making in a gambling task. Behavioral Neuroscience, 121, 257-263.

ROBINSON, O. J., CHARNEY, D. R., OVERSTREET, C., VYTAL, K. \& GRILLON, C. 2012a. The adaptive threat bias in anxiety: Amygdala-dorsomedial prefrontal cortex coupling and aversive amplification. Neuroimage, 60, 523-529.

ROBINSON, O. J., OVERSTREET, C., ALLEN, P. S., PINE, D. S. \& GRILLON, C. 2012b. Acute Tryptophan Depletion Increases Translational Indices of Anxiety but not Fear: Serotonergic Modulation of the Bed Nucleus of the Stria Terminalis[quest]. Neuropsychopharmacology, 37, 1963-1971.

ROBINSON, O. J., VYTAL, K., CORNWELL, B. R. \& GRILLON, C. 2013. THE IMPACT OF ANXIETY UPON COGNITION: PERSPECTIVES FROM HUMAN THREAT OF SHOCK STUDIES. Frontiers in Human Neuroscience, 7.

SCHMITZ, A. \& GRILLON, C. 2012. Assessing fear and anxiety in humans using the threat of predictable and unpredictable aversive events (the NPU-threat test). Nat. Protocols, 7, 527-532.

SPIELBERGER, C. D., GORSUCH, R. L. \& LUSHENE, R. E. 1970. The state-trait anxiety inventory. Palo Alto, Calif: Consulting Psychologists Press Inc.

VAN DEN BOS, R., HARTEVELD, M. \& STOOP, H. 2009. Stress and decision-making in humans: Performance is related to cortisol reactivity, albeit differently in men and women. Psychoneuroendocrinology, 34, 1449-1458.

VYTAL, K. E., OVERSTREET, C., CHARNEY, D. R., ROBINSON, O. J. \& GRILLON, C. 2014. Sustained anxiety increases amygdala-dorsomedial prefrontal coupling: a mechanism for maintaining an anxious state in healthy adults. Journal of Psychiatry \& Neuroscience : JPN, 39, 321-329.

WALTEROS, C., SÁNCHEZ-NAVARRO, J. P., MUÑOZ, M. A., MARTíNEZ-SELVA, J. M., CHIALVO, D. \& MONTOYA, P. 2011. Altered associative learning and emotional decision making in fibromyalgia. Journal of Psychosomatic Research, 70, 294-301.

WERNER, N. S., DUSCHEK, S. \& SCHANDRY, R. 2009. Relationships between affective states and decisionmaking. International Journal of Psychophysiology, 74, 259-265. 


\section{Table $\mathbf{1}$ (on next page)}

Table 1

Parameters for the possible monetary outcomes associated with each deck, adapted from Cauffman et al. (2010). The net outcomes were equivalent to those in the original lowa Gambling Task (Bechara et al., 1994). 


\begin{tabular}{|l|c|c|c|c|}
\cline { 2 - 5 } \multicolumn{1}{c|}{} & \multicolumn{4}{c|}{ DECK } \\
\cline { 2 - 5 } & A & B & C \\
\hline Range & $-\$ 250$ to $\$ 100$ & $-\$ 1150$ to $\$ 100$ & $-\$ 25$ to $\$ 50$ & $-\$ 200$ to $\$ 50$ \\
\hline Probability of gain & $50 \%$ & $90 \%$ & $50 \%$ & $90 \%$ \\
\hline Probability of loss & $50 \%$ & $10 \%$ & $25 \%$ & $10 \%$ \\
\hline Probability of zero payoff & $0 \%$ & $0 \%$ & $25 \%$ & $0 \%$ \\
\hline Expected value (average & & & & \\
\hline $\begin{array}{l}\text { outcome over repeated } \\
\text { choices) }\end{array}$ & $-\$ 25$ & & & \\
\hline
\end{tabular}

3 


\section{Table 2 (on next page)}

Table 2

Behavioural data for good and bad decks in threat and safe conditions across all subjects. $\mathrm{RT}=$ reaction time in seconds (standard error of the mean). Choice $=$ proportion of cards chosen from that deck. 


\begin{tabular}{|c|c|c|c|c|c|c|c|c|}
\hline & \multicolumn{4}{|c|}{ Safe } & \multicolumn{4}{|c|}{ Threat } \\
\hline & \multicolumn{2}{|c|}{ Bad } & \multicolumn{2}{|c|}{ Good } & \multicolumn{2}{|c|}{ Bad } & \multicolumn{2}{|c|}{ Good } \\
\hline \multirow{2}{*}{$\begin{array}{l}\text { Cho } \\
\text { ice }\end{array}$} & \multicolumn{2}{|c|}{$0.656(0.032)$} & \multicolumn{2}{|c|}{$0.83(0.019)$} & \multicolumn{2}{|c|}{$0.649(0.03)$} & \multicolumn{2}{|c|}{0.843 (0.019) } \\
\hline & Play & Pass & Play & Pass & Play & Pass & Play & Pass \\
\hline RT & $\begin{array}{c}0.793 \\
(0.039)\end{array}$ & $\begin{array}{c}0.915 \\
(0.041)\end{array}$ & $\begin{array}{c}0.779 \\
(0.041)\end{array}$ & $\begin{array}{c}0.907 \\
(0.052)\end{array}$ & $\begin{array}{c}0.798 \\
(0.039)\end{array}$ & $\begin{array}{c}0.902 \\
(0.041)\end{array}$ & $\begin{array}{c}0.805 \\
(0.044)\end{array}$ & $\begin{array}{c}0.878 \\
(0.058)\end{array}$ \\
\hline
\end{tabular}

3 


\section{1}

Figure 1

Task schematic. Subjects are given the option to play or pass the deck highlighted in yellow. Outcomes are added or subtracted from the running total displayed at the bottom of the screen. Subjects completed one baseline block whilst safe from shock and one stress block at risk of shock (order counterbalanced).

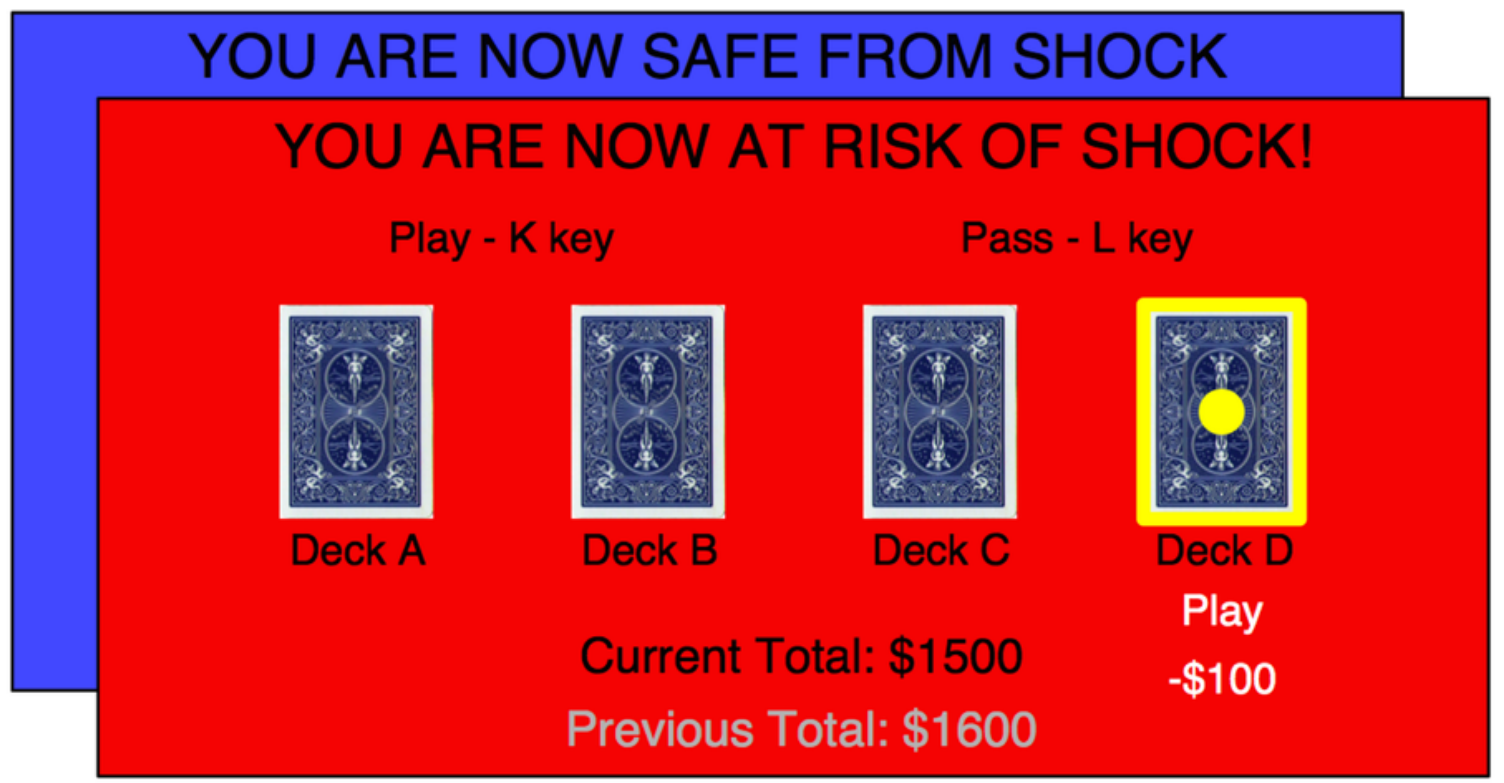


2

Figure 2

The effect of stress on participants' propensity to play cards on threat blocks (proportion of cards accepted under threat minus proportion accepted under safe) varies significantly with anxiety and depression symptoms, for disadvantageous but not advantageous decks. N.B. Raw depression scores are depicted but data were transformed with a square-root function for statistical analysis. 
Anxiety

옹

인

त्త

ธั

구

(ึ)

듬

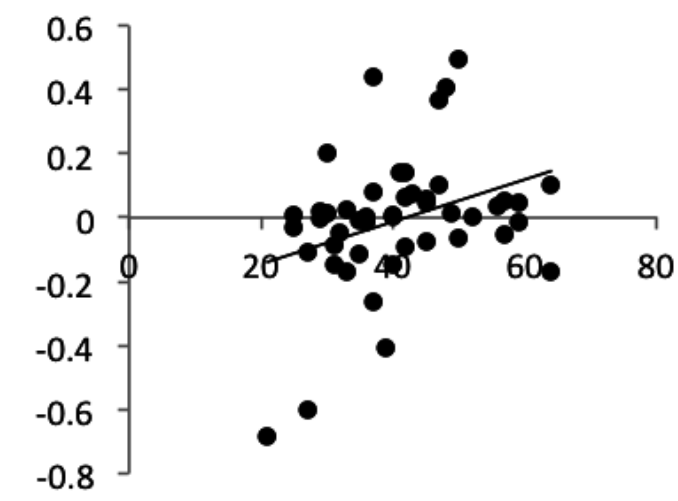

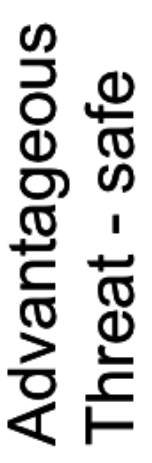
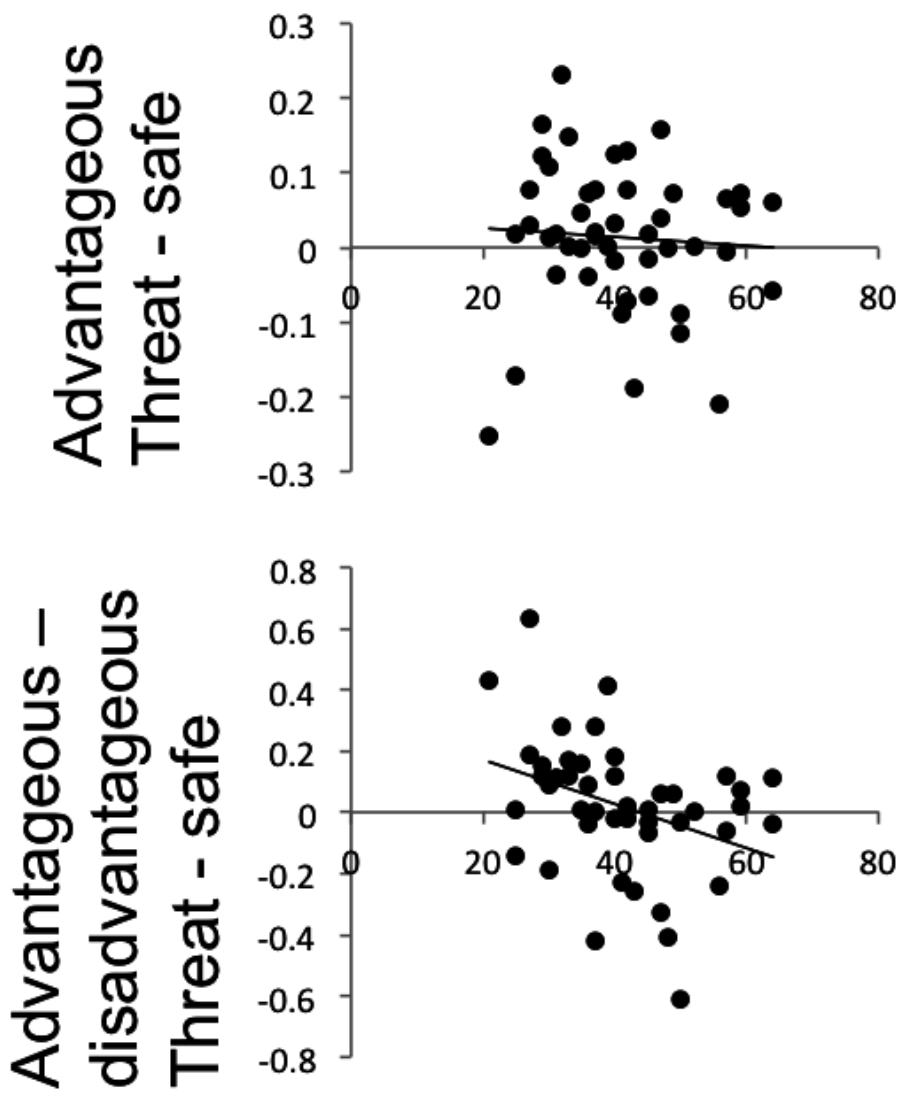

Depression
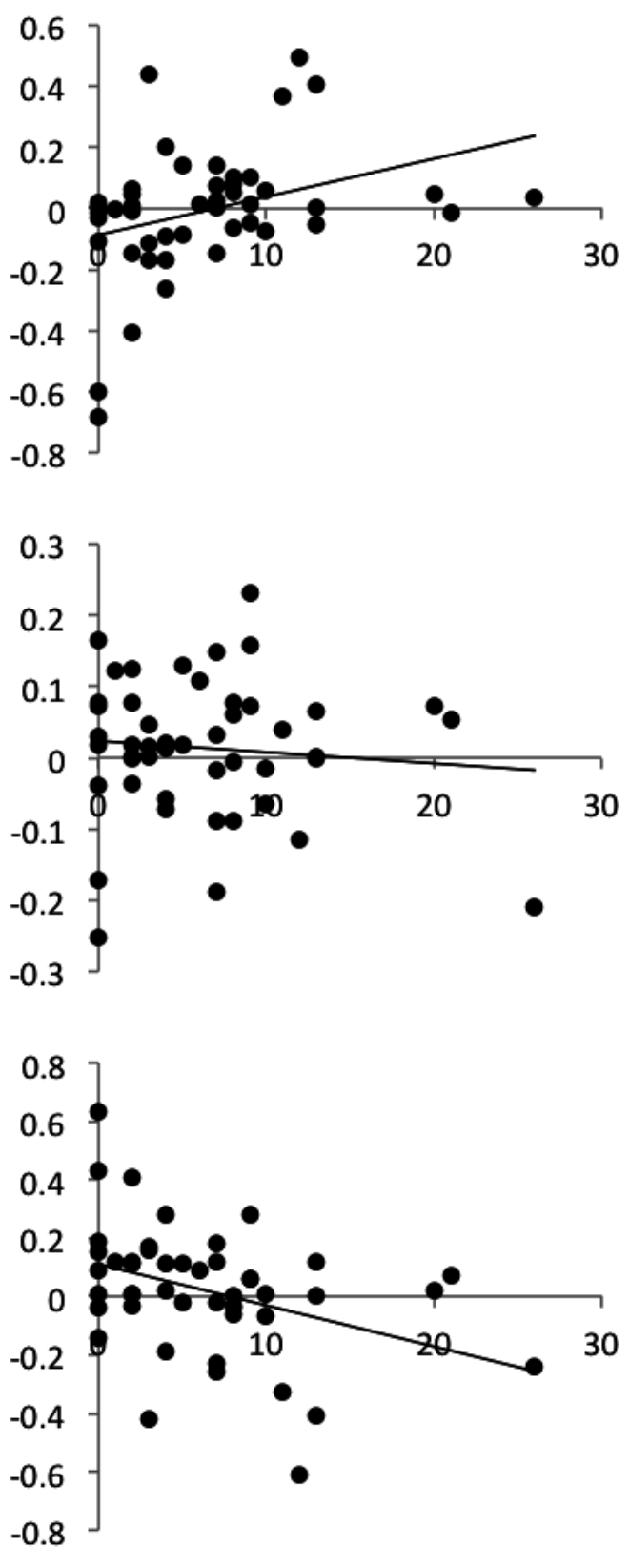